\title{
AN APPROACH TO MEASURING WEBSITE QUALITY IN THE RURAL TOURISM INDUSTRY BASED ON ATANASSOV INTUITIONISTIC FUZZY SETS
}

\author{
Dragisa Stanujkic, Edmundas Kazimieras Zavadskas, \\ Jolanta Tamošaitiené
}

\section{Introduction}

Tourism is a very important industry in today's global economy. Tourism also stimulates other industries significantly. The analysis of south-eastern European countries provides the initial framework for benchmarking the tourism performance of different countries, and determination of objectives and strategies for improving tourism competitiveness [48]. The quality aspect leads to the success of tourism development is any destination [26]. It is one of the sustainable tourism development [22].

In many rural areas in Serbia tourism has been recognized as one of the important segments that should ensure their sustainable economic development; this being the case with similar areas in other countries [3], [7], [9], [16], [17], [40], [41], [42]. One of these areas is Timocka Krajina (Timok frontier) located in eastern Serbia, on the border with Bulgaria and Romania. This region abounds in natural beauties such as mountains (Rtanj, Stol and the Stara Planina-the Old Mountain), gorges (Djerdapska Klisura - the Iron Gates of the Danube and Lazarev Kanjon - Lazar's Canyon), and caves (Lazareva Pecina Lazar's Cave and Rajkova Pecina - Rajko's Cave). Also worth mentioning is a natural stone bridge called the Vratnjanske Kapije (gates).

The importance of tourism potentials in Timocka Krajina has also been recognized in the project Stara Planina (the Old Mountain or the Balkan mountain range is an extension of the Carpathian mountain range, separated from it by the Danube River. This range runs $560 \mathrm{~km}$ from eastern Serbia eastward through central Bulgaria to Cape Emine on the Black Sea (Visit and meet Stara planina 2014) - New Network, which is co-funded by the EU through the Bulgaria-Serbia IPA Cross-border Programme.
A large number of websites contain all the necessary information regarding the natural beauties of the Stara Planina and its tourism potential, as well as other attractive locations in Timocka Krajina. There is a considerable diversity in these websites, which is probably the consequence of different purposes they have, then different amounts of funds available for their development and maintenance, as well as different levels of knowledge, skills and enthusiasm on the part of their webmasters.

The importance of the Internet and websites in the hotel and the rural tourism industry is discussed in a number of studies, such as: [4], [23], [45], [46], [47]. In a series of papers Law [30], [31], [33] considered the importance of the websites in the hotel industry, and proposed a fuzzy multiple criteria decision-making model for their evaluation. Akincilar \& Dagdeviren [1] proposed the Multiple Criteria Decision Making (MCDM) model for evaluating hotel websites based on the AHP and PROMETHEE methods. A similar approach, based on AHP and VIKOR methods, was proposed by [18].

It is also important to note that Haile [19] states that an average visitor do not spend more than 15 seconds actively on the website, or even less than 10 seconds. It is also significant that the number of such visitors is not negligible, and that according to Haile [19] it is a staggering $55 \%$.

Therefore, developing a MCDM model that allows us to determine how much firsttime visitors are really satisfied with the quality of a website or what the satisfaction level of their expectations really is could be of great significance. Using such a model, a webmaster could achieve the following: timely determine the quality of the website, compare the website with competitive websites, and identify weaknesses of the website. 
In order to more realistically collect attitudes of the respondents, the planned model should provide an easy way to collect as much realistic attitudes of surveyed respondents as possible.

Intuitionistic fuzzy set is a very useful tool to depict uncertainty. Lots of multi-criteria group decision making methods under intuitionistic fuzzy environment have been developed [50]. Intuitionistic fuzzy prioritized operators and their application in multi-criteria group decision making are presented [12], [53], [54]. Data envelopment analysis is a non-parametric and linear programming based approach to appraise the relative efficiency of a set of congruent units [50]. For the fuzzy environment the intuitionistic trapezoidal fuzzy numbers density aggregation operators can be used [35], [49]. For the data analysis the comparison of accuracy in ranking alternatives performing generalized fuzzy average functions are used [29]. Chen [13] presented the Interval-Valued Atanassov's Intuitionistic Fuzzy Environment Inclusion-Based LINMAP method for Multiple Criteria Decision Analysis for efficiency evaluation under uncertainty. Therefore, in this approach, the proposed MCDM model is based on the use of Atanassov Intuitionistic Fuzzy Sets (IFSs) together with DEA method [20].

Due to the reasons mentioned above, the rest of this paper is organized as follows: Section 1 considers some basic definitions and notations related to IFSs. Section 2 considers the criteria for evaluating the quality of websites with special emphasis on the criteria that can be used in the hotel and rural tourism industry. Section 3 proposes the MCDM framework for evaluating the quality of websites from the first-time visitors' point of view. Finally, Section 4 offers a numerical example with the aim of explaining the proposed methodology in detail. After that comes the conclusion.

\section{Preliminaries}

This section considers some basic concepts of IFSs, Intuitionistic Fuzzy Numbers (IFNs) and linguistic variables, which are relevant to the proposing a framework for evaluating websites from first-time visitors' point of view.

\subsection{Basic concepts of Intuitionistic Fuzzy Sets}

Fuzzy sets (FS) theory was first introduced by Zadeh [51] and this theory, unlike classical sets theory, allows partial membership to a set.
Let $X$ be universe of discourse. Then a fuzzy set $\widetilde{A}$, can be defined as follows

$$
\widetilde{A}=\left\{\left\langle x, \mu_{A}(x)\right\rangle \mid x \in X\right\},
$$

where: $\mu_{A}: X \rightarrow[0,1]$ is a membership function, and $\mu_{A}(x)$ denotes the degree of membership of the element $\mathrm{x}$ to the set $\widetilde{A}$ [51].

In addition to belonging to a set, in IFSs theory Atanassov [5] also introduced not belonging to a set. Therefore, an IFS $\widetilde{A}$ in $X$ can be defined as follows:

$$
\widetilde{A}=\left\{\left\langle x, \mu_{A}(x), v_{A}(x)\right\rangle \mid x \in X\right\},
$$

where: $\mu_{A}(x)$ and $v_{A}(x)$ denote the degree of membership and the degree of nonmembership of the element $x$ to the set $A$, respectively; $\mu_{A}: X \rightarrow[0,1]$ and $v_{A}: X \rightarrow[0,1]$; $0 \leq \mu_{A}(x)+v_{A}(x) \leq 1$.

In addition, a very useful parameter, called the degree of indeterminacy of $x$ to $A$, is defined in the IFSs theory, as follows

$$
\pi_{A}(x)=1-\mu_{A}(x)-v_{A}(x),
$$

under the following condition

$\pi_{A}(x) \in[0,1]$.

Basic operations on IFSs. The operations of addition and multiplication on IFSs were defined by Atanassov [6]. Let $\widetilde{A}=\left\langle\mu_{A}, v_{A}\right\rangle$ and $\widetilde{B}=\left\langle\mu_{B}, v_{B}\right\rangle$ be two IFSs. Then, the basic operations on IFSs can be defined as follows:

$$
\begin{aligned}
& \widetilde{A}+\widetilde{B}=\left\langle\mu_{A}+\mu_{B}-\mu_{A} \mu_{B}, v_{A} v_{B}\right\rangle, \\
& \widetilde{A} \cdot \widetilde{B}=\left\langle\mu_{A} \mu_{B}, v_{A}+v_{B}-v_{A} v_{B}\right\rangle .
\end{aligned}
$$

Score function of IFSs. Chen and Tan [11] introduced a Score function to provide a method for comparing IFSs. Let $\widetilde{A}=\left\langle\mu_{A}, v_{A}\right\rangle$ be an IFS. Then,

$$
S_{A}=\mu_{A}-v_{A},
$$

where SA denotes value of Score function, and $S_{\tilde{A}} \in[-1,1]$. 
$\widetilde{B}$ Ranking of IFSs. Let $\widetilde{A}=\left\langle\mu_{A}, v_{A}\right\rangle$ and $\widetilde{B}=\left\langle\mu_{B}, v_{B}\right\rangle$ be two IFSs. Then, the ranking of IFSs on the basis of Score function can be made as follows:

$$
\begin{array}{lll}
\widetilde{A}>\widetilde{B} & \text { if } & S_{A}>S_{B} \\
\widetilde{A} \cong \widetilde{B} & \text { if } & S_{A}=S_{B} \\
\widetilde{A}<\widetilde{B} & \text { if } & S_{A}<S_{B}
\end{array}
$$

Intuitionistic Weighted Arithmetic Mean of IFSs. Let $\widetilde{A}_{j}=\left\langle\mu_{A_{i}}, v_{A_{j}}\right\rangle$ be a collection of IFSs. The Intuitionistic Weighted Arithmetic Mean (IWAM) of dimensions $\mathrm{n}$ is a mapping $I W A M: R^{n} \rightarrow R$ that has an associated weighting vector $W=\left(w_{1}, w_{2}, \ldots, w_{n}\right)^{T}$ with $w_{j} \in[0,1]$ and $\sum_{j=1}^{n} w_{j}=1$, such as

$$
\begin{aligned}
& \operatorname{IWAM}\left(\widetilde{A}_{1}, \widetilde{A}_{2}, \ldots, \widetilde{A}_{n}\right)=\sum_{j=1}^{n} w_{j} \widetilde{A}_{j}= \\
& =\left(1-\prod_{j=1}^{n}\left(1-\mu_{A_{j}}\right)^{w_{j}}, \prod_{j=1}^{n}\left(v_{A_{j}}\right)^{w_{j}}\right)
\end{aligned}
$$

\subsection{Intuitionistic Fuzzy Numbers}

As with the FSs theory, the IFSs theory also proposes several shapes of IFNs. The significant shapes are the triangular and trapezoidal ones when the linear membership functions are used, while with the bell-shaped ones the non-linear membership functions are preferred.

In addition to the above mentioned shapes, the singleton shape can be pointed out as a characteristic one. A singleton IFN $A$, $\widetilde{A}=\left\langle a, a^{\prime}\right\rangle$, shown in Figure 1 , is defined with the membership $\mu_{A}(x)$ and non-membership $v_{A}(x)$ function, respectively, as follows:

$$
\begin{aligned}
& \mu(x)=\left\{\begin{array}{cc}
1 & x=a, \\
0 & \text { otherwise; }
\end{array},\right. \\
& \nu(x)=\left\{\begin{array}{cc}
1 & x=a^{\prime} \\
0 & \text { otherwise; }
\end{array},\right.
\end{aligned}
$$

where: parameter $a$ indicates the most promising value that describes belonging to a set, parameter $a^{\prime}$ indicates the most promising value that describes not-belonging to a set.

Basic operations on IFNs. Let $\widetilde{A}=\left\langle a, a^{\prime}\right\rangle$ and $\widetilde{B}=\left\langle b, b^{\prime}\right\rangle$ be two IFNs. According to

\section{Fig. 1: A singleton IFN}

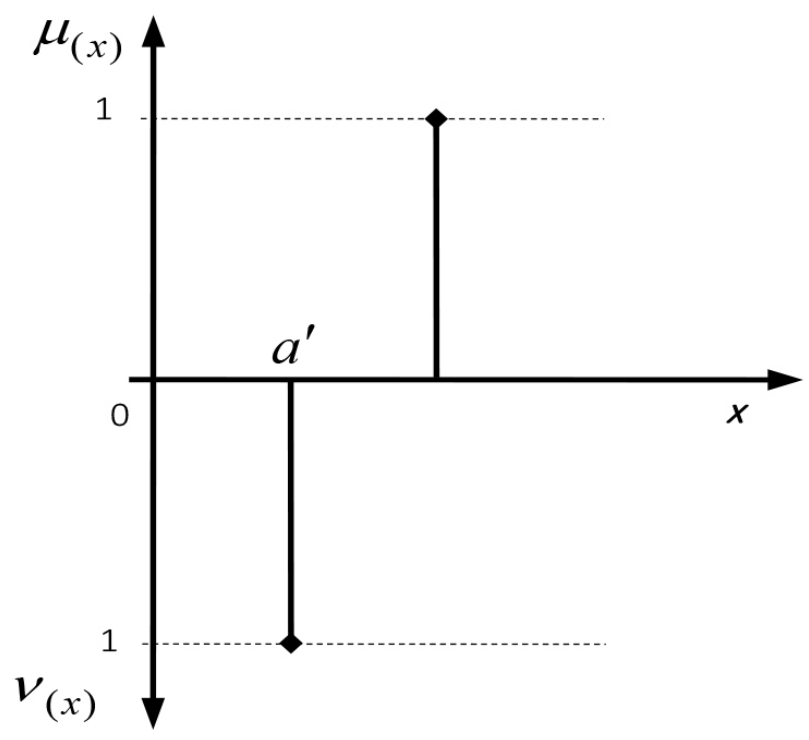


Eq. (5) and Eq. (6), the operations of addition and multiplication on IFNs are as follows:

$$
\begin{aligned}
& \widetilde{A}+\widetilde{B}=\left\langle a+b-a b, a^{\prime} b^{\prime}\right\rangle \\
& \widetilde{A} \cdot \widetilde{B}=\left\langle a b, a^{\prime}+b^{\prime}-a^{\prime} b^{\prime}\right\rangle
\end{aligned}
$$

Score function of IFNs. Let be a singleton IFN. Then, the score of is as follows

$$
S_{\tilde{A}}=a-a^{\prime}
$$

where $S_{\widetilde{A}} \in[-1,1]$.

As in the case of IFSs, the Score function can be used to rank the IFNs, as it is previously shown.

Intuitionistic Weighted Arithmetic Mean of singleton IFNs. Let $\widetilde{A}_{j}=\left\langle a_{j}, a_{j}^{\prime}\right\rangle$ be a collection of singleton IFNs. According to Eq. (9), the IWAM of singleton IFNs is as follows

$$
\begin{aligned}
& \operatorname{IWAM}\left(\widetilde{A}_{1}, \widetilde{A}_{2}, \ldots, \widetilde{A}_{n}\right)= \\
& =\left(1-\prod_{j=1}^{n}\left(1-a_{j}\right)^{w_{j}}, \prod_{j=1}^{n}\left(a_{j}^{\prime}\right)^{w_{j}}\right) .
\end{aligned}
$$

\subsection{Intuitionistic Fuzzy Linguistic Variables}

The linguistic variables have been extensively used by many authors for solving various decision-making problems, and as a result, numerous linguistic scales, as well as variables, are also proposed. In this approach, a specific linguistic scale adapted to work with singleton IFNs is proposed. The proposed linguistic scale is shown in Table 1.

In this approach, the same linguistic variables are used for expressing a level of satisfaction and a level of dissatisfaction. In order to satisfy the condition (4), i.e. the condition according to which the degree of indeterminacy should be less than or equal to one, the acceptable combinations of linguistic variables that can be used for expressing satisfaction and dissatisfaction levels are shown in Table 2.

\section{Criteria for Evaluating Websites}

A large number of studies, published in many scientific and professional journals, have been devoted to website quality evaluation. The approach proposed by Boyd Collins in late 1995 can be identified as the first formal approach of this type. His model, intended for librarians, was based on six criteria developed by combining evaluation criteria for printed media, and considering what was relevant for websites [38]. The criteria proposed by Collins are: Contents, Authority, Organizations, Searchability, Graphic design and Innovation use.

A very important approach to website quality evaluation was also proposed by Kapoun [27]. According to him, the following criteria are identified as crucial: Accuracy, Authority, Objectivity, Currency, and Coverage. Based on the proposed evaluation, the Kapoun approach has the acronym AAOCC.

\section{Tab. 1: Linguistic variables for expressing satisfaction and dissatisfaction levels}

\begin{tabular}{l|c}
\multicolumn{1}{c|}{ Linguistic variable } & The corresponding numerical values \\
\hline Completely (C) & 0.995 \\
\hline Very high (VH) & 0.875 \\
\hline High (H) & 0.750 \\
\hline Moderate high (MH) & 0.625 \\
\hline Moderate (M) & 0.500 \\
\hline Moderate low (ML) & 0.375 \\
\hline Low (L) & 0.250 \\
\hline Very Low (VL) & 0.125 \\
\hline Insignificantly Little (IL) & 0.005 \\
\hline
\end{tabular}




\begin{tabular}{l|c|c|c|c|c|c|c|c|c}
\multirow{2}{*}{ Satisfaction level } & \multicolumn{7}{|c}{ Dissatisfaction level and degree of indeterminacy } \\
\cline { 2 - 9 } & C & VH & H & MH & M & ML & L & VL & EL \\
\hline Completely (C) & & & & & & & & & 0.000 \\
\hline Very High (VH) & & & & & & & & 0.000 & 0.120 \\
\hline High (H) & & & & & & & 0.000 & 0.125 & 0.245 \\
\hline Moderate High (MH) & & & & & & 0.000 & 0.125 & 0.250 & 0.370 \\
\hline Moderate (M) & & & & & 0.000 & 0.125 & 0.250 & 0.375 & 0.495 \\
\hline Moderate Low (ML) & & & & 0.000 & 0.125 & 0.250 & 0.375 & 0.500 & 0.620 \\
\hline Low (L) & & & 0.000 & 0.125 & 0.250 & 0.375 & 0.500 & 0.625 & 0.745 \\
\hline Very Low (VL) & & 0.000 & 0.125 & 0.250 & 0.375 & 0.500 & 0.625 & 0.750 & 0.870 \\
\hline Insignificantly Little (IL) & 0.000 & 0.120 & 0.245 & 0.370 & 0.495 & 0.620 & 0.745 & 0.870 & 0.990 \\
\hline
\end{tabular}

Alexsander and Tate [2] and some librarians [8] confirmed the usability of the Kapoun approach while some other librarians slightly modified it. For example, Lydia [36] proposed the following six criteria: Authority, Accuracy, Objectivity, Currency, Coverage, and Appearance, which are to be applied when evaluating the quality of a website.

However, there are some librarians who have much more radical attitudes. Librarians at the California State University of Chico [10] proposed the use of the so-called CRAAP test, which contains a list of questions that are to determine whether the information on a particular website is reliable or not. Similarly to the Kapoun approach, the CRAAP test is also an acronym, i.e. it stands for the following criteria: Currency, Relevance, Authority, Accuracy, and Purpose.

It should be noted that there are views according to which the Kapoun approach is not suitable for evaluation of all types of websites [15]. Therefore, due to their specific characteristics and features, different websites are to use different evaluation criteria.

\subsection{Criteria for Evaluating Websites in the Tourism Industry}

In the literature can also be identified some studies that are devoted to measuring the quality of websites in tourism, i.e. in the hotel industry, and to defining a set of relevant evaluation criteria.
Law et al. [34] provided a comprehensive overview of the website evaluation in the tourism industry. According to Han and Mills [21] commented that the use of the websites in tourism marketing began in 1995, and that Murphy et al. [39] conducted a pioneer study that attempted to evaluate tourism and hospitality websites in an early stage of web development.

The approach proposed by Chung and Law [14] is one of the first approaches proposed for evaluating the quality of the websites in the hotel industry. This approach is based on the use of the following evaluation criteria: Facilities information, Customer contact information, Reservation information, Surrounding area information, and Management of websites; as well as the use of their sub-criteria.

Law and Cheung [32] identified five criteria that are important when determining the quality of hotel websites, i.e., Reservations information, Facilities information, Contact information, Surrounding area information, and Website management. On the basis of the conducted survey of Greek hotels websites, Zafiropoulos and Vrana [52] identified the following six criteria relevant to the hotel website quality measurement: Facilities information, Guest contact information, Reservation and prices information, Surrounding area information, Management of the website and company profile. For each of these criteria, Zafiropoulos and Vrana [52] also identified the relevant sub-criteria. 
Herrero and San Martin [23] identified the following three key attributes (criteria) important for tourism websites: information, interactivity, and navigability.

\subsection{Criteria for Evaluating Websites Devoted to the Promotion of Tourist Destinations from the First-Time Visitors' Point of View}

Unlike world famous tourist destinations, the less-known ones have to make a far greater effort in order to attract new visitors. If we assume that there are undecided tourists who use the web searching for new tourist destinations, then we can argue that the website's capability to catch and retain a firsttime visitor in just a few seconds is one of the important roles that website has.

In order to more precisely determine the impression the first-time visitors have, it is of essential importance that respondents understand the meaning of the evaluation criteria clearly. Therefore, this approach suggests the use of a smaller number of evaluation criteria.

There is also the second reason for using a small number of criteria and that is a short period of observation, which is the time the respondents have to look at the website before carrying out their evaluation in relation to the selected set of criteria.

Due to the above mentioned reasons, this approach proposes the following criteria to be used in assessing the overall impressions firsttime visitors have, i.e. the impression first-time visitors gain when visiting a website:

- Web page Environment. The adequate Web page Environment (En), which includes an attractive design, an efficient and logically organized menu system, search capabilities, a multi-language support, an appropriate color scheme and fonts, and finally the harmonious arrangement of website elements all have a significant impact on the impressions first-time visitors have.

When the respondents evaluate the website in relation to the criterion Web page environment, some of the following questions are to be considered: Is the website environment adequately designed? Is it designed to attract the attention of first-time visitors? and Is it appropriate for obtaining the required information?

- Content. The Content (Co) of the website is of a crucial significance. However, in a just few seconds first-time website visitors rather perform screening than reading the content.

When the first-time visitors evaluate the website in relation to the Content criterion, the following questions are to be taken into account: Does the web page contain the necessary information? Are the web pages organized in such a way so that the visitors could identify and find the information easily?

- Graphics. In the case of websites, especially the websites devoted to the promotion of tourist destinations, the appropriately designed Graphical elements $(\mathrm{Gr})$ stored on the home page, as well as on other web pages, can have a significant positive impact on the visitors' attention.

Regarding the graphics, the following is to be considered: Do web pages contain the adequate graphic elements? and, Are the graphic elements adequately located on the web pages?

- Authority. The evidence supporting the Authority $(\mathrm{Au})$ of the information on the website is certainly welcome. For first-time visitors, it is important that such evidence exists and that it can be spotted easily.

\section{A Framework for Evaluating Websites Devoted to Promoting Tourist Destinations from the First-Time Visitors' Point of View}

As previously mentioned, a significant number of average visitors spend less than 15 seconds, not so rarely less than 10 seconds, on a website. In this short period of time it is necessary to introduce a website visitor to the main goal and basic ideas of the website, and thus obtain his or her attention. Therefore, the following requirements have been taken into consideration during the proposed model forming:

- Period of observation. The period of time that the respondents have to observe the evaluated website should not be longer than time that average visitors spend on websites before their abandonment, i.e. the time of observation should not be longer than 10 seconds. In other words, during the evaluation of websites the respondents at any time may leave the website and begin the next step of the proposed evaluation procedure, but the period of observation should not be longer than 10 seconds. 
- Simplicity in use. In order to obtain the real attitudes of ordinary respondents, the proposed model has to be user-friendly and easy to use. Therefore, the proposed model should use a smaller number of criteria whose meaning is clearly understood by all respondents.

- Completeness. In order to compensate the use of a small number of evaluation criteria, used for gathering attitudes of respondents, the proposed model should be based on the use of IFNs, which allows the respondents to express the level of their satisfaction and dissatisfaction regarding the complex evaluation criteria.

- Qualitative versus quantitative. It is clear that human beings often prefer to use qualitative descriptions as opposed to quantitative values. Therefore, the linguistic scale, adopted to the use of IFNs, for evaluating websites in relation to the selected criteria were presented to the respondents.

- Precision. It is known that quantitative values are more precise than qualitative variables. Therefore, after transforming linguistic variables in the corresponding quantitative values, respondents were allowed to adjust it if it is necessary. In addition, respondents were allowed to, if they want, neglect the use of linguistic variables and use numeric values for evaluation.

- Consistency. Using the degree of indeterminacy and condition (4) the respondents whose responses cannot be accepted can be identified. Such respondents should be introduced with omissions, and they should get the opportunity to correct their answers. However, if after performed correction the obtained responses do not satisfy the condition (4) then such respondent should be rejected as inadequate, i.e. as respondent who does not want to cooperate or cannot understood the use of IFSs.

\subsection{The procedure for evaluating websites devoted to promoting tourist destinations from the first- time visitors' point of view}

In order to fulfill the above mentioned requirements, which basically means that firsttime visitors are satisfied with a particular website promoting a particular tourist destination, the following procedure is suggested:

Step 1. Prepare the respondents for evaluation. In this step, the respondents are prepared to evaluate websites in relation to the selected criteria.

This step includes a short introduction to IFNs, meaning of the membership function and non-membership function, and their use for expressing satisfaction and dissatisfaction about something. In order to make the respondents more familiar with the use of IFNs, this step also presupposes that the respondents are guided to perform the evaluation using IFNs in some simple examples.

Within this step, the respondents are also introduced to the criteria that will be used to evaluate the websites and their meaning.

Step 2. Collect the data for website evaluation. In this step, clearly can be identified the following sub-steps:

1. Visit and observe the website, no longer than 10 seconds;

2. Rate the website in relation to the selected set of the evaluation criteria;

3. Transform the linguistic variables into the recommended numerical values, and modify the numerical values if necessary; and

4. Check the consistency of responses, and made corrections if the condition (4) is not satisfied.

The usual procedure used in the website evaluation normally involves more respondents, which means that the sub-steps 1-4 should be repeated for each respondent.

Step 3. Determine the group performance ratings. The group performance ratings can be determined using Eq. (15).

Step 4. Determine the significance of evaluation criteria. The procedures for determining the significance of criteria, more often called criteria weights or shorter weights, is usually not part of many significant MCDM methods. However, the weights may have significant influence on the results and that is why different authors suggest different procedures when determining weights [37], such as pair-wise comparisons [43], [44], Delphi method [24], Entropy approach [25], and SWARA method [28].

Each of the mentioned procedures, i.e. methods, can be used when determining the weights of the criteria relevant to evaluating the website quality. 
Step 5. Calculate the overall performance rating for each of the considered websites. Based on the obtained group performance ratings and the criteria weights, the overall performance rating of each of the considered alternatives can be determined using Eq. (15).

Step 6. Calculate the Score function, for each of the considered websites. The overall performance ratings of the alternatives obtained in step 5 are IFNs. In order to perform their ranking it is necessary to determine the values of their Score functions using Eq. (14).

Step 7. Determine the ranking order of the alternatives. The considered alternatives are ranked in the ascending order and the alternative with the highest $\mathrm{Si}$ is the best ranked.

\subsection{The Procedure for Determining the Website's Weaknesses}

In addition to website ranking, the proposed model can also be used to evaluate a website, or more precisely, to determine its weaknesses.

In such cases, the performance ratings are considered only for the selected website. By using steps 1, 2 and 4 of the above discussed procedure, webmasters can determine the performance ratings for the observed website as well as the criteria weights.

The remaining part of the procedures can be specified as follows:

Step 5a. Calculate the overall ratings for the considered website in relation to each criterion. In this step, the performance ratings in the decision-making matrix should be transposed and, instead of all performance ratings of alternatives, the performance rating of the considered alternative in relation to each criterion should be calculated.

Step 6a. Calculate the Score function, for each criterion. The performance ratings of the alternative obtained in step 5a are IFNs. In order to determine the weaknesses of the considered website, it is necessary to determine the value of the Score function for each criterion, using Eq. (14).

Step 7a. Determine the "worst criterion" and analyze the website's weaknesses. The obtained performance ratings are ranked in a descending order, whereby the criterion with the lowest value of $\mathrm{Si}$ is highlighted as "the weakest criterion", i.e. the criteria in relation to which the website has failed.

Besides, considering the satisfaction and dissatisfaction levels of "the weakest criterion", it can be estimated to what extent the website visitors' expectations are satisfied. Such an analysis can also be made with the remaining criteria.

Based on such analysis, some appropriate activities, with the aim of improving the quality of the website, can be performed.

\section{Numerical Example}

In this example some partial results obtained from the case study dealing with the quality assessment of the websites which promote tourism potentials of the Old Mountain are presented, with the aim to verify the effectiveness of the framework proposed in Section 3 and to identify its potential weaknesses.

In accordance with the proposed procedure, the chosen websites are evaluated on the basis of a set of selected evaluation criteria. The ratings obtained from three respondents, related to the quality of the four selected websites, are shown in Tables 3, 4 and 5.

In order to be evaluated further, the ratings from Tables 3, 4 and 5 are transformed into a form more suitable for evaluation, as shown in Tables 6, 7 and 8. During this transformation, the linguistic variables are transformed into the corresponding numerical values in accordance with the data from Table 1; wherein the fields marked as "-", i.e. fields that are not filled during the interviewing, were transformed into the linguistic variables "IL", that is the value 0.005 .

The group performance ratings obtained using IWAM operator, i.e. using Eq. (15), are shown in Table 9. During this transformation, it is assumed that all the respondents have the same significance that is $1 / \mathrm{K}$, which is 0.333 .

The criteria weights, shown in Table 9, were determined using SWARA method, on the basis of the data collected from a relatively small number of respondents.

On the basis of the data from Table 9, the overall performance ratings are also determined using Eq. (15). Then, using Eq. (14), the value of the Score function for each of the considered websites was determined.

The overall performance ratings, values of Score function, and ranking order of consideration websites are shown in Table 10.

As it can be seen from Table 10, the alternative $A 2$ is the most appropriate one among the considered websites.

In addition to websites ranking, the proposed model can be used for their evaluation, i.e. 
Tab. 3: The ratings obtained from the first of the three respondents

\begin{tabular}{c|c|c|c|c|c|c|c|c}
\hline Criteria & \multicolumn{2}{|c|}{ En } & \multicolumn{2}{c|}{ Co } & \multicolumn{2}{c|}{ Gr } & \multicolumn{2}{c}{ Au } \\
\hline Alternatives & $\boldsymbol{\mu}$ & $\boldsymbol{v}$ & $\boldsymbol{\mu}$ & $\boldsymbol{v}$ & $\boldsymbol{\mu}$ & $\boldsymbol{v}$ & $\boldsymbol{\mu}$ & $\boldsymbol{v}$ \\
\hline$A_{1}$ & $\mathrm{ML}$ & $\mathrm{VL}$ & $\mathrm{ML}$ & $\mathrm{IL}$ & $\mathrm{ML}$ & $\mathrm{ML}$ & $\mathrm{L}$ & - \\
\hline$A_{2}$ & $\mathrm{H}$ & $\mathrm{VL}$ & $\mathrm{M}$ & $\mathrm{ML}$ & $\mathrm{VH}$ & $\mathrm{IL}$ & $\mathrm{VH}$ & $\mathrm{IL}$ \\
\hline$A_{3}$ & $\mathrm{ML}$ & $\mathrm{L}$ & $\mathrm{M}$ & $\mathrm{L}$ & $\mathrm{L}$ & $\mathrm{IL}$ & $\mathrm{L}$ & - \\
\hline$A_{4}$ & $\mathrm{ML}$ & $\mathrm{MH}$ & $\mathrm{MH}$ & $\mathrm{ML}$ & $\mathrm{MH}$ & $\mathrm{VL}$ & $\mathrm{L}$ & - \\
\hline
\end{tabular}

Tab. 4: The ratings obtained from the second of the three respondents

\begin{tabular}{c|c|c|c|c|c|c|c|c}
\hline Criteria & \multicolumn{2}{|c|}{ En } & \multicolumn{2}{c|}{ Co } & \multicolumn{2}{c|}{ Gr } & \multicolumn{2}{c}{ Au } \\
\hline Alternatives & $\boldsymbol{\mu}$ & $\boldsymbol{v}$ & $\boldsymbol{\mu}$ & $\boldsymbol{v}$ & $\boldsymbol{\mu}$ & $\boldsymbol{v}$ & $\boldsymbol{\mu}$ & $\boldsymbol{v}$ \\
\hline$A_{1}$ & 0.4 & 0.1 & 0.6 & 0.3 & $\mathrm{M}$ & - & 0.2 & - \\
\hline$A_{2}$ & $\mathrm{M}$ & $\mathrm{VL}$ & 0.5 & - & $\mathrm{VH}$ & - & $\mathrm{ML}$ & $\mathrm{H}$ \\
\hline$A_{3}$ & 0.5 & 0.3 & 0.4 & 0.2 & $\mathrm{ML}$ & - & $\mathrm{ML}$ & - \\
\hline$A_{4}$ & $\mathrm{MH}$ & $\mathrm{L}$ & $\mathrm{H}$ & $\mathrm{ML}$ & $\mathrm{ML}$ & $\mathrm{L}$ & $\mathrm{L}$ & - \\
\hline
\end{tabular}

Tab. 5: The ratings obtained from the third of the three respondents

\begin{tabular}{c|c|c|c|c|c|c|c|c}
\hline Criteria & \multicolumn{2}{|c|}{ En } & \multicolumn{2}{c|}{ Co } & \multicolumn{3}{c|}{ Gr } & \multicolumn{2}{c}{ Au } \\
\hline Alternatives & $\boldsymbol{M}$ & $\boldsymbol{v}$ & $\boldsymbol{\mu}$ & $\boldsymbol{v}$ & $\boldsymbol{\mu}$ & $\boldsymbol{v}$ & $\boldsymbol{\mu}$ & $\boldsymbol{v}$ \\
\hline$A_{1}$ & $\mathrm{~L}$ & - & $\mathrm{H}$ & $\mathrm{ML}$ & $\mathrm{ML}$ & $\mathrm{L}$ & $\mathrm{ML}$ & - \\
\hline$A_{2}$ & $\mathrm{~L}$ & - & $\mathrm{MH}$ & $\mathrm{L}$ & $\mathrm{ML}$ & $\mathrm{L}$ & $\mathrm{ML}$ & $\mathrm{L}$ \\
\hline$A_{3}$ & $\mathrm{M}$ & $\mathrm{ML}$ & $\mathrm{VH}$ & - & $\mathrm{L}$ & - & $\mathrm{MH}$ & $\mathrm{ML}$ \\
\hline$A_{4}$ & $\mathrm{ML}$ & $\mathrm{M}$ & $\mathrm{VH}$ & $\mathrm{L}$ & $\mathrm{L}$ & - & $\mathrm{ML}$ & - \\
\hline
\end{tabular}

Source: own

Tab. 6: The ratings obtained from the first of the three respondents in a numerical form

\begin{tabular}{|c|c|c|c|c|}
\hline Criteria & \multirow{2}{*}{ En } & \multirow{2}{*}{ Co } & \multirow{2}{*}{ Gr } & \multirow{2}{*}{$\mathrm{Au}$} \\
\hline Alternatives & & & & \\
\hline$A_{1}$ & $<0.375,0.125>$ & $<0.375,0.005>$ & $<0.375,0.375>$ & $<0.250,0.005>$ \\
\hline$A_{2}$ & $<0.750,0.125>$ & $<0.500,0.375>$ & $<0.875,0.005>$ & $<0.875,0.005>$ \\
\hline$A_{3}$ & $<0.375,0.250>$ & $<0.500,0.250>$ & $<0.250,0.005>$ & $<0.250,0.005>$ \\
\hline$A_{4}$ & $<0.375,0.625>$ & $<0.625,0.375>$ & $<0.625,0.125>$ & $<0.250,0.005>$ \\
\hline
\end{tabular}


Tab. 7: The ratings obtained from the second of the three respondents in a numerical form

\begin{tabular}{c|c|c|c|c} 
Criteria & \multirow{2}{*}{ En } & Co & Gr & Au \\
\cline { 1 - 4 } Alternatives & $<0.400,0.100>$ & $<0.600,0.300>$ & $<0.500,0.005>$ & $<0.200,0.005>$ \\
\hline$A_{1}$ & $<0.500,0.125>$ & $<0.500,0.005>$ & $<0.875,0.005>$ & $<0.375,0.750>$ \\
\hline$A_{2}$ & $<0.500,0.300>$ & $<0.400,0.200>$ & $<0.375,0.005>$ & $<0.375,0.005>$ \\
\hline$A_{3}$ & $<0.625,0.250>$ & $<0.750,0.375>$ & $<0.375,0.250>$ & $<0.250,0.005>$ \\
\hline$A_{4}$ & \multicolumn{1}{|c|}{}
\end{tabular}

Source: own

Tab. 8: The ratings obtained from the third of the three respondents in a numerical form

\begin{tabular}{|c|c|c|c|c|}
\hline Criteria & \multirow{2}{*}{ En } & \multirow{2}{*}{ Co } & \multirow{2}{*}{ Gr } & \multirow{2}{*}{$\mathrm{Au}$} \\
\hline Alternatives & & & & \\
\hline$A_{1}$ & $<0.375,0.125>$ & $<0.375,0.005>$ & $<0.375,0.375>$ & $<0.250,0.375>$ \\
\hline$A_{2}$ & $<0.750,0.125>$ & $<0.500,0.375>$ & $<0.875,0.005>$ & $<0.875,0.750>$ \\
\hline$A_{3}$ & $<0.375,0.250>$ & $<0.500,0.250>$ & $<0.250,0.005>$ & $<0.250,0.375>$ \\
\hline$A_{4}$ & $<0.375,0.625>$ & $<0.625,0.500>$ & $<0.625,0.125>$ & $<0.250,0.375>$ \\
\hline
\end{tabular}

Source: own

\section{Tab. 9: The group performance ratings}

\begin{tabular}{c|c|c|c|c} 
Criteria & \multirow{2}{*}{ En } & Co & Gr & Au \\
\cline { 1 - 4 } Alternatives & $\mathbf{0 . 2 8}$ & $\mathbf{0 . 2 5}$ & $\mathbf{0 . 2 4}$ & $\mathbf{0 . 2 3}$ \\
\hline Weights & $<0.383,0.116>$ & $<0.461,0.020>$ & $<0.419,0.089>$ & $<0.233,0.005>$ \\
\hline$A_{1}$ & $<0.685,0.125>$ & $<0.500,0.089>$ & $<0.875,0.005>$ & $<0.786,0.027>$ \\
\hline$A_{2}$ & $<0.419,0.266>$ & $<0.468,0.232>$ & $<0.294,0.005>$ & $<0.294,0.005>$ \\
\hline$A_{3}$ & $<0.473,0.461>$ & $<0.672,0.413>$ & $<0.555,0.158>$ & $<0.250,0.005>$ \\
\hline$A_{4}$ & \multicolumn{2}{c}{}
\end{tabular}

The ranking order of the analyzed websites obtained on the basis of Score function

\begin{tabular}{c|c|c|c} 
Alternatives & IWAM & $\boldsymbol{S}_{\mathbf{i}}$ & Rank \\
\hline$A_{1}$ & $<0.382,0.034>$ & 0.174 & 3 \\
\hline$A_{2}$ & $<0.741,0.037>$ & 0.352 & 1 \\
\hline$A_{3}$ & $<0.377,0.040>$ & 0.169 & 4 \\
\hline$A_{4}$ & $<0.512,0.123>$ & 0.195 & 2 \\
\hline
\end{tabular}


Tab. 11: The responses obtained from the three respondents for alternative $A_{4}$

\begin{tabular}{l|c|c|c|c}
$\begin{array}{c}\text { Criteria } \\
\text { Alternatives }\end{array}$ & En & Co & Gr & Au \\
\hline Weights & 0.28 & 0.25 & 0.24 & 0.23 \\
\hline Respondent I & $<0.375,0.625>$ & $<0.625,0.375>$ & $<0.625,0.125>$ & $<0.250,0.005>$ \\
\hline Respondent II & $<0.625,0.250>$ & $<0.750,0.375>$ & $<0.375,0.250>$ & $<0.250,0.005>$ \\
\hline Respondent III & $<0.375,0.625>$ & $<0.625,0.500>$ & $<0.625,0.125>$ & $<0.250,0.375>$ \\
\hline
\end{tabular}

Source: own

\section{Tab. 12: Transposed decision-making table}

\begin{tabular}{c|c|c|c|c} 
Criteria & Weights & Resp. I & Resp. II & Resp. III \\
\hline $\mathrm{En}$ & 0.28 & $<0.375,0.625>$ & $<0.625,0.25>$ & $<0.375,0.625>$ \\
\hline $\mathrm{Co}$ & 0.25 & $<0.625,0.375>$ & $<0.75,0.375>$ & $<0.625,0.500>$ \\
\hline $\mathrm{Gr}$ & 0.24 & $<0.625,0.125>$ & $<0.375,0.25>$ & $<0.625,0.125>$ \\
\hline $\mathrm{Au}$ & 0.23 & $<0.250,0.005>$ & $<0.250,0.005>$ & $<0.250,0.005>$ \\
\hline
\end{tabular}

Source: own

\section{Tab. 13: Transposed decision-making table}

\begin{tabular}{c|c|c|c} 
Criteria & IWAM & $\boldsymbol{S}_{\boldsymbol{i}}$ & Rank \\
\hline $\mathrm{En}$ & $<0.473,0.461>$ & 0.012 & 4 \\
\hline $\mathrm{Co}$ & $<0.672,0.413>$ & 0.259 & 3 \\
\hline $\mathrm{Gr}$ & $<0.555,0.158>$ & 0.397 & 1 \\
\hline $\mathrm{Au}$ & $<0.250,0.005>$ & 0.245 & 2 \\
\hline
\end{tabular}

Source: own

for estimating the level of first-time visitors' satisfaction, based on the opinions of one or more respondents. This feature can also be considered as one of the most important characteristics of the proposed model.

Below is shown the process of analyzing the weaknesses of the website A4 which was ranked as the second in the previous example. The responses obtained from the three respondents, related to website $\mathrm{A} 4$, are shown again in Table 11. For the purpose of further processing, the performance ratings from Table 11 are transposed, as shown in Table 12. The values shown in Table 13 were calculated using Eq. (15) and Eq. (14).

As it can be concluded from Table 13, the considered website A4 has the weakest ratings in relation to the Web page environment criterion. It is evident that by improving the web page environment also growing the satisfaction of website visitors. By forming different variants of websites, i.e. different variants of web pages, and by their evaluation, the webmaster can improve the quality of his or her website, and thus increase the number of visitors who will spend more time on the website.

In addition, except the moderate value of the satisfaction level, it is possible here to observe the moderate value of dissatisfaction level which indicates that the design of the website has a weakness related to the Web page environment criterion.

The second criterion related to the weaknesses of the website is Authority. As it can be seen, in this case the satisfaction level have a low value, while the value of the dissatisfaction level is negligible, which indicates that the website does not contain 
enough evidence that confirms its Authority, or such evidence was not clearly visible.

Using such analyses a webmaster can take adequate actions and modify the website in accordance with the needs of its visitors.

\section{Conclusions}

Some of current researches indicate that many first-time visitors spend a very short time on a particular webpage when accessing a particular website. Therefore, if we presume that the acquisition of new customers is one of the features of a website, such a website should be designed to obtain the attention of the first-time visitors and to keep them.

Various elements of websites essential for obtaining the attention of website visitors and crucial for their satisfaction, have been identified in numerous studies. As opposed to these studies, this paper focuses on designing a multiple criteria model that could realistically determine the quality of the website from the first-time visitors' view. In order to form a realistic model, this approach uses a small number of criteria that are evaluated using Atanassov fuzzy sets. Also, in order to create a model which as simple as possible, based on Atanassov fuzzy sets, this approach uses the Singleton Intuitionistic Fuzzy Numbers.

The use of the proposed approach for assessing the quality of some websites which promote tourist potentials of the Old Mountain indicates the applicability and efficiency of the proposed approach, but also indicates some its weaknesses, such as: Firstly, the use of Atanassov fuzzy sets can be quite complex for ordinary respondents, and therefore, before the evaluation itself, it is necessary to introduce respondents to their use; and Secondly, the respondents must be accurately introduced to the meaning of the criteria used in the proposed model.

Finally, with the proposed, or with some other, set of criteria, while retaining a relatively small number of criteria, the proposed approach, or more precisely framework, can be successfully applied to the tourism and hotels industry, as well as to other areas, with the aim of determining the quality of the websites from the first-time visitors' point of view.

\section{References}

[1] AKINCILAR, A., DAGDEVIREN, M. A hybrid multi-criteria decision making model to evaluate hotel websites. International Journal of Hospitality Management. 2014, Vol. 36, pp. 263-271. ISSN 0278-4319. DOI: 10.1016/j. ijhm.2013.10.002.

[2] ALEXANDER, J.E., TATE, M.A. Web wisdom: How to evaluate and create information quality on the Web. Mahwah, NJ: Lawrence Erlbaum Associates. 1999. ISBN 0805831231.

[3] ANDERSON, E., BAKIR, A., WICKENS, E. Rural Tourism Development in Connemara, Ireland. Tourism Planning \& Development. 2015, Vol. 12 , No. 1, pp. $73-86$. ISSN 21568316. DOI: $10.1080 / 21568316.2014 .965844$.

[4] ANDREOPOULOU, Z., et al. Internet marketing for sustainable development and rural tourism. International Journal of Business Information Systems. 2014, Vol. 16, No. 4, pp. 446-461. ISSN 1746-0980. DOI: 10.1504/ IJBIS.2014.063931.

[5] ATANASSOV, K.T. Intuitionistic fuzzy sets. Fuzzy sets and Systems. 1986, Vol. 20, No. 1, pp. 87-96. ISSN 0165-0114. DOI: 10.1016/ S0165-0114(86)80034-3.

[6] ATANASSOV, K.T. New operations defined over the intuitionistic fuzzy sets. Fuzzy sets and Systems. 1994. Vol. 61, No. 2, pp. 137142. ISSN 0165-0114. DOI: 10.1016/01650114(94)90229-1.

[7] BARKE, M. Rural tourism in Spain. International Journal of Tourism Research. 2004, Vol. 6, No. 3, pp. 137-149. ISSN 15221970. DOI: $10.1002 /$ jtr.480.

[8] BECK, S.E. The Good, The Bad \& The Ugly: or, Why It's a Good Idea to Evaluate Web Sources [online]. New Mexico State University Library, 1999 [cit. 2014-11-29]. 5 p. (PDF). Available from: http://www.ucolick.org/ max/ Astro18-2014/GoodBadUgly.pdf.

[9] BEL, F., et al. Domestic demand for tourism in rural areas: Insights from summer stays in three French regions. Tourism Management. 2015, Vol. 46, pp. 562-570. ISSN 0261-5177. DOI: 10.1016/j.tourman.2014.07.020.

[10] California State University at Chico. Evaluating Information - Applying the CRAAP Test [online]. California State University at Chico, 2010. [cit. 2014-11-27]. 1 p. (PDF). Available from: http://www.csuchico.edu/lins/ handouts/eval_websites.pdf.

[11] CHEN, S.M., TAN, J.M. Handling multicriteria fuzzy decision-making problems based on vague set theory. Fuzzy sets and systems. 1994, Vol. 67, No. 2, pp. 163-172. ISSN 0165-0114. DOI: 10.1016/01650114(94)90084-1. 
[12] CHEN, T.-Y. Data construction process and qualiflex-based method for multiple-criteria group decision making with interval-valued intuitionistic fuzzy sets. International Journal of Information Technology \& Decision Making. 2013, Vol. 12 , No. 3, pp. 425-467. ISSN 02196220. DOI: 10.1142/S021962201350017X.

[13] CHEN, T.-Y. The Inclusion-Based LINMAP Method for Multiple Criteria Decision Analysis within an Interval-Valued Atanassov's Intuitionistic Fuzzy Environment. International Journal of Information Technology \& Decision Making. 2014, Vol. 13, No. 6, pp. 13251360. ISSN 0219-6220. DOI: 10.1142/ S0219622014500722.

[14] CHUNG, T., LAW, R. Developing a Performance Indicator for Hotel Websites. International Journal of Hospitality Management. 2003, Vol. 22, No. 1, pp. 343-358. ISSN 02784319. DOI: $10.1016 / S 0278-4319(02) 00076-2$.

[15] DAHL, C. Undergraduate research in the public domain: The evaluation of non-academic sources online. Reference Services Review. 2009 , Vol. 37 , No. 2, pp. 155-163. ISSN 00907324. DOI: $10.1108 / 00907320910957198$.

[16] DEVESA, M., LAGUNA, M., PALACIOS, $A$. The role of motivation in visitor satisfaction: Empirical evidence in rural tourism. Tourism Management. 2010, Vol. 31, No. 4, pp. 547-552. ISSN 0261-5177. DOI: 10.1016/j. tourman.2009.06.006.

[17] EFTEKHARI, A.R., et al. Application of integration multi-criteria decision making method and GIS in identification of rural regions with ecotourism potential case study: river valley tourism in Tehran Providence. Rural Research. 2013, Vol. 4, No. 3, pp. Pe641-Pe660. ISSN 7373-2008.

[18] FU, H.P., et al. Using fuzzy AHP and VIKOR for benchmarking analysis in the hotel industry. The Service Industries Journal. 2011, Vol. 31, No. 14, pp. 2373-2389. ISSN 02642069. DOI: $10.1080 / 02642069.2010 .503874$.

[19] HAILE, T. What You Think You Know About the Web Is Wrong [online]. Time Inc. Network, 2014 [cit. 2014-08-06]. Available from: http:// time.com/12933/what-you-think-you-knowabout-the-web-is-wrong/.

[20] HAJIAGHA, S.H.R., et al. An intuitionistic fuzzy data envelopment analysis for efficiency evaluation under uncertainty: case of a finance and credit institution. E+M Ekonomie a Management. 2013, Vol. 16, No. 1, pp. 128137. ISSN 1212-3609.
[21] HAN, J.H., MILLS, J.E. Zero acquaintance benchmarking at travel destination websites: what is the first impression that national tourism organizations try to make? International Journal of Tourism Research. 2006, Vol. 8, No. 6, pp. 405-430. ISSN 1522-1970. DOI: 10.1002/jtr.581. [22] HASHEMKHANI ZOLFANI, S., et al. Sustainable tourism: a comprehensive literature review on frameworks and applications. Economic Research-Ekonomska Istraživanja. 2015, Vol. 28, No. 1, pp. 1-30. ISSN 1331677X. DOI: 10.1080/1331677X.2014.995895.

[23] HERRERO, A., SAN MARTIN, H. Developing and testing a global model to explain the adoption of websites by users in rural tourism accommodations. International Journal of Hospitality Management. 2012, Vol. 31, No. 4, pp. 1178-1186. ISSN 0278-4319. DOI: $10.1016 /$ j.ijhm.2012.02.005.

[24] HWANG, C.L., LIN, M.J. Group Decision Making Under Multiple Criteria: Methods and Applications. Berlin: Springer-Verlag, 1987. ISBN 978-3-642-61580-1.

[25] HWANG, C.L., YOON, K. Multiple attribute decision making: Methods and applications. Berlin: Springer Verlag. 1981. ISBN 978-3-64248318-9.

[26] JOVANOVIĆ, S., MILIĆ, V.J., KRSTIĆ, B. Homogeneity analysis of south-eastern European countries according to tourism competitiveness performances. Economic Research-Ekonomska Istraživanja. 2014, Vol. 27, No. 1, pp. 207-220. ISSN 1331-677X. DOI: 10.1080/1331677X.2014.952113.

[27] KAPOUN, J. Teaching undergrads web evaluation - a guide for library instruction. College and Research Libraries News. 1998, Vol. 59, No. 7, pp. 522-523. ISSN 0099-0086. [28] KERSULIENE, V., ZAVADSKAS, E.K., TURSKIS, Z. Selection of rational dispute resolution method by applying new step - wise weight assessment ratio analysis (SWARA). Journal of Business Economics and Management. 2010, Vol. 11, No. 2, pp. 243-258. ISSN 1611-1699. DOI: 10.3846/jbem.2010.12. [29] KOSAREVA, N., KRYLOVAS, A. Comparison of accuracy in ranking alternatives performing generalized fuzzy average functions. Technological and Economic Development of Economy. 2013, Vol. 19, No. 1, pp. 162-187. ISSN 2029-4913. DOI: 10.3846/20294913.2012.763072.

[30] LAW, R. A fuzzy multiple criteria decisionmaking model for evaluating travel websites. 
Asia Pacific Journal of Tourism Research. 2007, Vol. 12, No. 2, pp. 147-159. ISSN 10941665. DOI: $10.1080 / 10941660701243372$.

[31] LAW, R. Fuzzy evaluation of hotel websites. In: Advanced Data Mining and Applications. Berlin, Heidelberg: Springer, 2005. pp. 507-514. ISBN 978-3-540-31877-4. DOI: 10.1007/11527503_61.

[32] LAW, R., CHEUNG, C. Weighing of hotel website dimensions and attributes. In: FREW, A.J. (Ed.). Information and communication technologies in tourism. New York: Springer Wien, 2005. pp. 327-334. ISBN 978-3-21124148-6. DOI: 10.1007/3-211-27283-6_32.

[33] LAW, R., HSU, C.H. Importance of hotel website dimensions and attributes: perceptions of online browsers and online purchasers. Journal of Hospitality \& Tourism Research. 2006, Vol. 30, No. 3, pp. 295-312. ISSN 10963480. DOI: $10.1177 / 1096348006287161$.

[34] LAW, R., QI, S., BUHALIS, D. Progress in tourism management: $A$ review of website evaluation in tourism research. Tourism management. 2010, Vol. 31, No. 3, pp. 297-313. ISSN 0261-5177. DOI: 10.1016/j. tourman.2009.11.007.

[35] LIU, P., YU, X. Density aggregation operators based on the intuitionistic trapezoidal fuzzy numbers for multiple attribute decision making. Technological and Economic Development of Economy. 2013, Vol. 19, Iss. Supplement 1, pp. S454-S470. ISSN 20294913. DOI: 10.3846/20294913.2013.881436.

[36] LYDIA, M., OLSON LIBRARY. Evaluating internet sources: A library resource guide [online]. Northern Michigan University, 2009 [cit. 2014-11-27]. Available from http://library. nmu.edu/guides/userguides/webeval.htm.

[37] MA, J., FAN, Z.P., HUANG, L.H. A subjective and objective integrated approach to determine attribute weights. European Journal of Operational Research. 1999, Vol. 112, No. 2, pp. 397-404. ISSN 0377-2217. DOI: 10.1016/S0377-2217(98)00141-6.

[38] MERWE, R., BEKKER, J. A framework and methodology for evaluating e-commerce web sites. Internet Research: Electronic Networking Applications and Policy. 2003, Vol. 13, No. 5, pp. 330-341. ISSN 1066-2243. DOI: 10.1108/10662240310501612.

[39] MURPHY, J., et al. Hotel Management and Marketing on the Internet An Analysis of Sites and Features. Cornell Hotel and Restaurant Administration Quarterly. 1996, Vol. 37,
No. 3, pp. 70-82. ISSN 1938-9655. DOI: 10.1016/0010-8804(96)86817-0.

[40] PARK, D.B., YOON, Y.S. Developing sustainable rural tourism evaluation indicators. International Journal of Tourism Research. 2011, Vol. 13, No. 5, pp. 401-415. ISSN 15221970. DOI: 10.1002/jtr.804.

[41] RANDELLI, F., ROMEI, P., TORTORA, M. An evolutionary approach to the study of rural tourism: The case of Tuscany. Land Use Policy. 2014, Vol. 38, pp. 276-281. ISSN 0264-8377. DOI: 10.1016/j.landusepol.2013.11.009.

[42] RID, W., EZEUDUJI, I.O., PROBSTLHAIDER, U. Segmentation by motivation for rural tourism activities in the Gambia. Tourism Management. 2014, Vol. 40, pp. 102-116. ISSN 0261-5177. DOI: 10.1016/j.tourman.2013.05.006. [43] SAATY, T.L. A scaling method for priorities in hierarchical structures. Journal of Mathematical Psychology. 1977, Vol. 15, Iss. 3, pp. 234-281. ISSN 0022-2496. DOI: 10.1016/0022-2496(77)90033-5.

[44] SAATY, T.L. The Analytical Hierarchy Process: Planning, Priority Setting, Resource Allocation. New York: McGraw-Hill, 1980. pp. 287. ISBN 978-0070543713.

[45] SAN MARTIN, H., HERRERO, A. Influence of the user's psychological factors on the online purchase intention in rural tourism: Integrating innovativeness to the UTAUT framework. Tourism Management. 2012, Vol. 33, Iss. 2, pp. 341-350. ISSN 0261-5177. DOI: 10.1016/j. tourman.2011.04.003.

[46] VASSILIADIS, C.A., FOTIADIS, A., PIPER, L.A. Analysis of rural tourism websites: the case of Central Macedonia. Tourismos: An international multidisciplinary journal of tourism. 2013, Vol. 8, Iss. 1, pp. 247-263. ISSN 1790-8418. [47] Visit and meet Stara planina [online]. 2014 [cit. 2014-11-24]. Available from: http://www. staraplanina.eu.

[48] VUJKO, A., GAJIC, T. Opportunities for tourism development and cooperation in the region by improving the quality of tourism services - the 'Danube Cycle Route' case study. Economic Research-Ekonomska Istraživanja. 2014, Vol. 27, Iss. 1, pp. 847-860. ISSN 1331677X. DOI: 10.1080/1331677X.2014.975517.

[49] WAN, S., DONG, J. Multi-Attribute Group Decision Making with Trapezoidal Intuitionistic Fuzzy Numbers and Application to Stock Selection. Informatica. 2014, Vol. 25, No. 4, pp. 663-697. ISSN 0868-4952. DOI: 10.15388/ Informatica.2014.34. 


\section{Informační management}

[50] YU, D. Intuitionistic fuzzy prioritized operators and their application in multi-criteria group decision making. Technological and Economic Development of Economy. 2013, Vol. 19, Iss. 1, pp. 1-21. ISSN 2029-4913. DOI: 10.3846/20294913.2012.762951.

[51] ZADEH, L.A. Fuzzy sets. Information and control. 1965, Vol. 8, Iss. 3, pp. 338353. ISSN 1462-3889. DOI: 10.1016/S00199958(65)90241-X.

[52] ZAFIROPOULOS, C., VRANA, V. A framework for the evaluation of hotel websites: The case of Greece. Information Technology \& Tourism. 2006, Vol. 8, pp. 239-254. ISSN 10983058. DOI: $10.3727 / 109830506778690812$.

[53] ZAVADSKAS, E.K., et al. The IntervalValued Intuitionistic Fuzzy MULTIMOORA Method for Group Decision Making in Engineering. Mathematical Problems in Engineering. 2015, Vol. 2015, Article ID 560690, 13 pp. ISSN 15635147. DOI: 10.1155/2015/560690.

[54] ZENG, S., et al. A Projection method for multiple attribute group decision making with intuitionistic fuzzy information. Informatica. 2013, Vol. 24, Iss. 3, pp. 485-503. ISSN 0868-4952.
Assoc. Prof. Dragisa Stanujkic,Ph.D.

Megatrend University

Faculty of Management in Zajecar

Graduate School of Computer Sciences dragisa.stanujkic@fmz.edu.rs

Prof. Edmundas Kazimieras Zavadskas, PhD, DSc, Dr h. c. mult

Vilnius Gediminas Technical University Research Institute of Smart BuildingTechnologies Department of Construction Technology and Management edmundas.zavadskas@vgtu.It

Assoc. Prof. Jolanta Tamošaitienè, Ph.D. Vilnius Gediminas Technical University Civil Engineering Faculty Research Institute of Smart Building Technologies Department of Construction Technology and Management, jolanta.tamosaitiene@vgtu.It 


\section{AN APPROACH TO MEASURING WEBSITE QUALITY IN THE RURAL TOURISM INDUSTRY BASED ON ATANASSOV INTUITIONISTIC FUZZY SETS}

\section{Dragisa Stanujkic, Edmundas Kazimieras Zavadskas, Jolanta Tamošaitienè}

Attracting new customers can be identified as one of the key roles websites play in the tourism and hotels industry that can be of special importance for less known tourist destinations, especially for rural tourism. However, some of current researches indicate that many first-time visitors spend a very short time on a particular webpage when accessing a particular website. Therefore, if we presume that the acquisition of new customers is one of the features of a website, such a website should be designed to obtain the attention of the first-time visitors and to keep them.

Various elements of websites essential for obtaining the attention of website visitors and crucial for their satisfaction have been identified in numerous studies. As opposed to these studies, this paper focuses on designing a multiple criteria model that could realistically determine the quality of the website from the first-time visitors' point of view. In order to form a realistic multiple criteria decision making model, the proposed approach is based on the use of a smaller number of criteria that are evaluated using Atanassov fuzzy sets. Also, in order to create a model which as simple as possible, based on Atanassov fuzzy sets, this approach uses the Singleton Intuitionistic Fuzzy Numbers.

The use of the proposed approach for assessing the quality of some websites which promote tourist potentials of the Old Mountain indicates the applicability and efficiency of the proposed approach.

Finally, with the proposed, or with some other, set of criteria, while retaining a relatively small number of criteria, the proposed approach can be successfully applied to the tourism and hotels industry, as well as to other areas, with the aim of determining the quality of the websites from the first-time visitors' point of view.

Key Words: Website quality, website evaluation, rural tourism, intuitionistic fuzzy sets, satisfaction level, multiple criteria decision making.

JEL Classification: D81, C61, C44.

DOI: 10.15240/tul/001/2015-4-013 